\title{
Frailty inclusive care in acute and community-based settings: a systematic review protocol
}

\author{
Carmel L. Montgomery ${ }^{1,2^{*}}$ (D), Gareth Hopkin', Sean M. Bagshaw ${ }^{2,3}$, Erin Hessey ${ }^{4}$ and Darryl B. Rolfson ${ }^{4}$
}

\begin{abstract}
Background: Frailty is a known risk factor for an array of adverse outcomes including more frequent and prolonged health services use and high health care costs. Aging of the population has implications for care provision across the care continuum, particularly for people living with frailty. Despite known risks associated with frailty, there has been limited research on care pathways that address the needs of persons living with frailty. Our study aims to review and examine, in a rigorous way, the quality of evidence for multi-component interventions and care pathways focused on frailty.
\end{abstract}

Methods: A comprehensive electronic search strategy will be used to identify studies that evaluate multicomponent interventions or care pathways for persons living with frailty. The search strategy will include terms for frailty, multi-component interventions, effectiveness, and cost effectiveness applied to the following databases: MEDLINE (OVID), EMBASE (OVID), CINAHL (EBSCO), Cochrane Central Register of Controlled Trials (CENTRAL), and Cochrane Database of Systematic Reviews. An adapted search for Google Scholar and gray literature databases will also be used. References of included studies will be hand-searched for additional citations of frailty-inclusive care. Known experts and corresponding authors of identified articles will be contacted by email to identify further eligible studies. Risk of bias will be assessed using the Effective Public Health Practice Project Quality Assessment tool. Data will be extracted from eligible studies and it is anticipated that narrative analysis will be used. If studies with sufficient homogeneity are found, then pooled effects will be reported using meta-analysis.

Discussion: This review will appraise the evidence currently available on multi-component frailty interventions. Results will inform on clinical pathway development for people living with frailty across the care continuum and will guide future research to address gaps in the literature and areas in need of further development.

Systematic review registration: PROSPERO CRD42020166733

Keywords: Frailty, Multi-component interventions, Cost effectiveness

\footnotetext{
* Correspondence: carmelm@ualberta.ca

${ }^{1}$ Institute of Health Economics, 120010405 Jasper Avenue, Edmonton,

Alberta T5J 3N4, Canada

${ }^{2}$ Department of Critical Care Medicine, Faculty of Medicine and Dentistry,

University of Alberta, 2-124 Clinical Sciences Building, 1135083 Ave,

Edmonton, Alberta T6G 2G3, Canada

Full list of author information is available at the end of the article
}

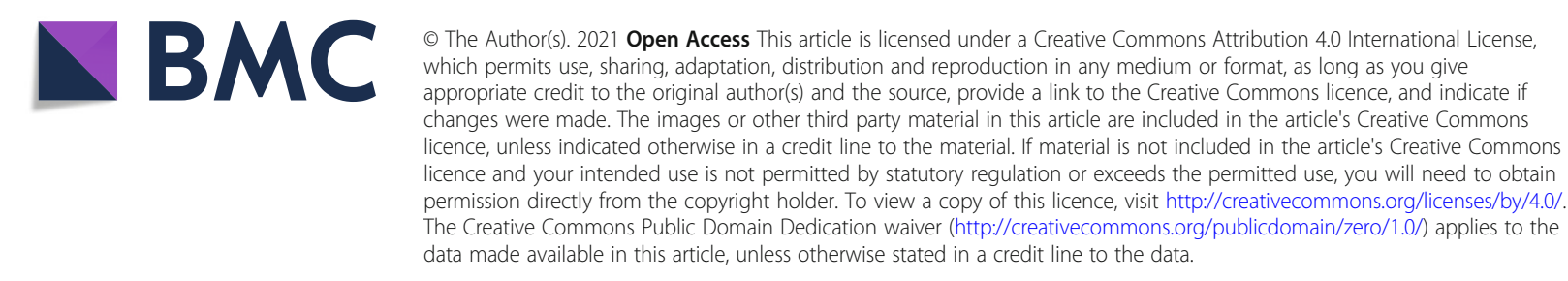




\section{Background}

The general health and functional status of patients prior to acute illness and other stressors are accepted as important determinants of hospital outcomes [1, 2]. This status can be captured by measuring frailty, an agerelated state of increased vulnerability with disproportionate changes in health status in response to stressors [3]. This creates the opportunity to develop and implement care protocols that are tailored to the health needs of persons who live with frailty.

As the worldwide population ages, the associated increase in prevalence of frailty across the care continuum presents urgent challenges to providing consistently appropriate care. Recent findings from cohort studies have shown prevalence of frailty in the Canadian adult community population is $8-24 \%$, increasing as age advances from $2 \%$ (18-34 years) to $20 \%$ ( $\geq 65$ years) [4, 5]. Frailty is common in assisted living environments (29\%), and among adults admitted to ICU (28-32\%) [6-9]. Frailty in hospitalized patients has been associated with gradient increases in hospital mortality, intensity of organ support, frequency and duration of health services use, and cost, when compared to non-frail patients [8-10].

Despite knowledge that frailty presents high risk for suboptimal outcomes, development and evaluation of comprehensive frailty interventions appears limited to specific circumstances such as improving patient flow after surgery (enhanced recovery after surgery [ERAS]), addressing frailty-related diseases or disability (e.g., delirium, dementia, depression), and providing focused interventions (e.g., nutrition, exercise) in acute and community-based care settings. The opportunity to view frailty as a multi-system syndrome is often overlooked by generic pathways where aspects of frailty are entirely unnoticed or assumed to be addressed by broad criteria such as chronological age. Frailty inclusive care, as defined herein, is an approach to care in any setting that starts with authentic frailty case-finding, followed by further assessment of the underlying vulnerabilities (components), and then leading to advance care planning, general measures to prevent or slow progression, and specific steps to address frailty components. Frailty inclusive care interventions may be generic, or may be specific to medical condition or care setting.

The primary aim of this project is to rigorously examine and document the quality of evidence for multicomponent interventions (e.g., frailty-inclusive care pathways) encompassing the broader patient journey through both community and hospital care. In so doing, we will be mindful of a variety of frailty constructs and measures, and the ways that frailty inclusive care has been operationalized using different frailty assessment measures, evaluated based on any comparators and outcomes across patient populations. This will directly inform further development and implementation of frailty-specific recommendations as part of a larger program of work in this area.

\section{Methods/design}

The full systematic review protocol is registered with the International Prospective Register of Systematic Reviews (PROSPERO) (ID CRD42020166733, April 28, 2020). A recent search of PROSPERO and the Cochrane Library indicated there were no registered reviews focused on the proposed topic. A Preferred Reporting Items for Systematic Reviews and Meta-Analyses Protocols (PRIS MA-P) checklist is included as an additional file [11] (Additional file 1).

\section{Search methodology and screening}

The search strategy will be developed by an information specialist, in partnership with the broader review team and peer-reviewed by a second information specialist. The initial search strategy will be translated for use across bibliographic databases and web search engines. We will identify potentially relevant studies by searching the following bibliographic databases from 2000 onwards (i.e., when frailty became a term used in research) in all languages, using a combination of keywords (i.e., free text) and MeSH terms: MEDLINE (OVID), EMBASE (OVID), CINAHL (EBSCO), Cochrane Central Register of Controlled Trials (CENTRAL), and Cochrane Database of Systematic Reviews (CDSR) (Table 1).

Other searches and strategies will include Google Scholar; ProQuest Dissertation and Theses Global; World Health Organization (WHO) International Clinical Trials Registry Platform (ICTRP) and clinicaltrials.gov for ongoing trials; published abstracts; and conference proceedings for 2 years prior to search date. An a priori list of websites which may contain eligible studies that have not been indexed will also be reviewed (Table 2).

Citations identified by the searches will be deduplicated in EndNote (Clarivate Analytics, v.9.), then uploaded to a Covidence (Veritas Health Innovation, Melbourne, Australia) library. Studies reported in languages other than English will be translated to English using Google Translate [12]. Two reviewers will independently screen the titles and abstracts of studies identified by the search (i.e., primary screening). Studies that meet the predetermined eligibility criteria from title and abstract review will undergo screening of full text (i.e., secondary screening) by two independent reviewers. Any disagreements will be resolved by consensus or the decision of a third party.

\section{Study selection}

We will include studies in any clinical setting that use an established frailty measure for case-finding. To 
Table 1 Search strategy-Medline

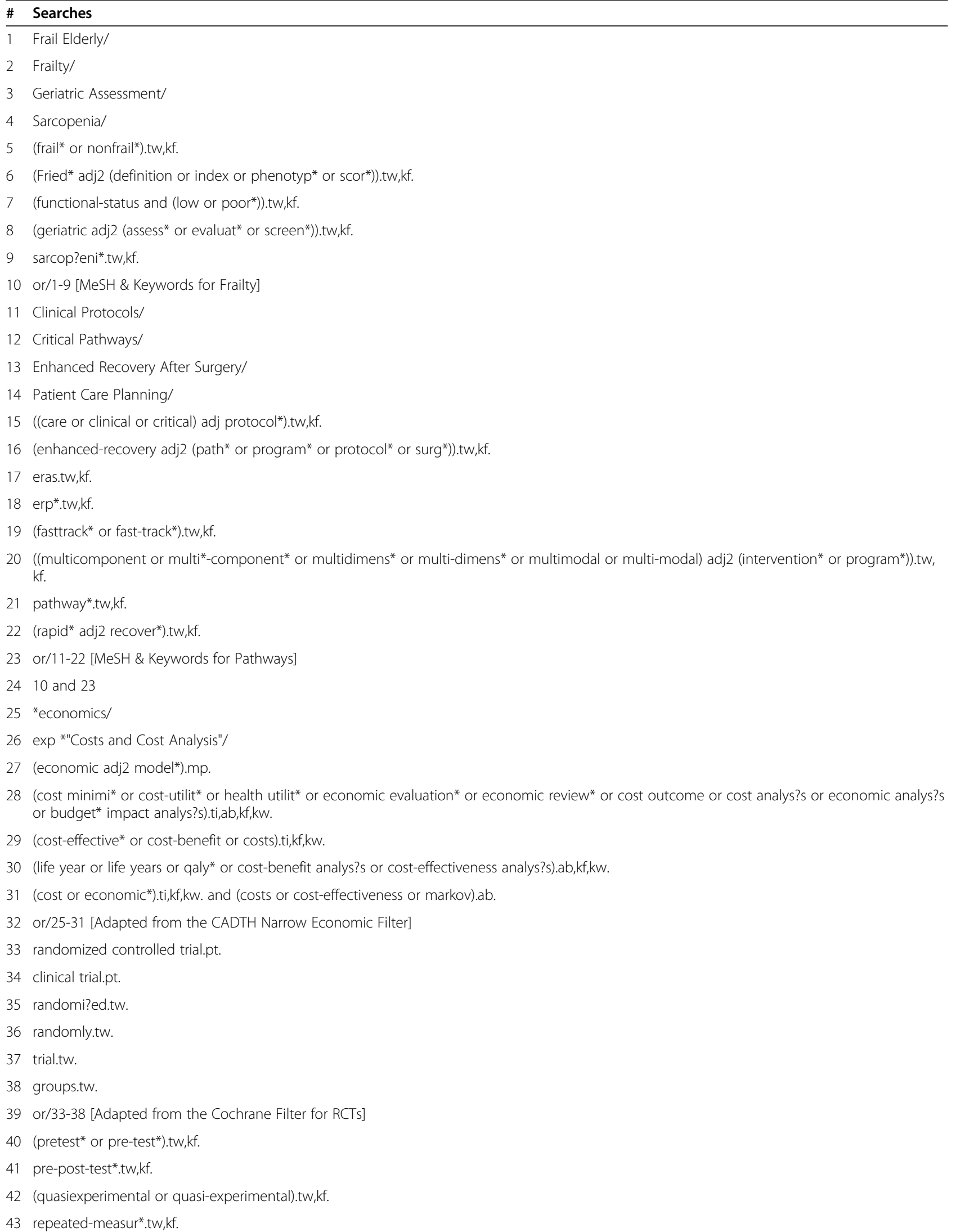


Table 1 Search strategy-Medline (Continued)

\begin{tabular}{ll}
\hline$\#$ & Searches \\
\hline 44 & time-series.tw,kf. \\
45 & (patient? or hospital\$).hw. and (study or studies).ti,hw. \\
46 (controlled adj3 before adj3 after).tw. \\
47 ((before adj10 (after or during)) and control).tw. \\
48 or/40-47 [MeSH \& keywords for quasiexperimental design] \\
4924 and (32 or 39 or 48 ) \\
50 limit 49 to yr="2000 -Current" \\
51 remove duplicates from 50 \\
\hline
\end{tabular}

improve consistency, a table of 93 eligible frailty measures was compiled from 13 literature reviews over the past decade, and classified based on the model of frailty (i.e., physical frailty, cumulative deficit, multidimensional, geriatric syndromes) and the method of administration (i.e., clinicianreport, clinician-judgment, self-report, performance-based, anthropometric, calculated) [13-25] (Table 3). To qualify as multi-component, more than one intervention must be present, targeting different components of frailty. The multicomponent intervention may include advance care planning, general measures to prevent or slow progression (e.g., a combined exercise and nutritional program), and detailed steps to address frailty. Specific interventions responding to components of frailty identified in particular individuals may include problems with cognition, mood, balance and mobility, continence, medications, and social support.

\section{Eligibility criteria Population}

The population of interest is all adult patients $(\geq 18$ years) defined as living with frailty, assessed by a validated frailty measurement, in acute, intermediate, or community-based care settings.

\section{Intervention}

We will identify multi-component interventions that have been developed and evaluated for their impact on individuals living with frailty, and the health services that

Table 2 Web sites for non-indexed study publications

https://www.cfn-nce.ca/
https://frailty.net/
https://frailty-sarcopenia.com/
https://anzssfr.org/
https://www.bgs.org.uk/
https://www.americangeriatrics.org/
https://thecanadiangeriatricssociety.wildapricot.org/
https://www.eugms.org/home.html

https://www.cfn-nce.ca/

https://frailty-sarcopenia.com/

https://anzssfr.org/

. comprise their care. Any intervention that can be applied to the broader patient journey through both community and hospital care will be included. Examples of interventions of interest include enhanced recovery after surgery (ERAS), multi-component fast track surgery programs or "prehabilitation," hospital to community transition processes, or care pathways that identify frailty and trigger comprehensive geriatric assessment (CGA) to address components of frailty. Interventions (e.g., pharmacological treatments, rehabilitative therapies, nutritional counseling) that are implemented independently or do not influence the overall care plan will be excluded, unless they are used in combination. Screening for frailty without intervention or CGA without the use of frailty measures to inform a personalized assessment or care plan will be excluded.

\section{Comparisons}

All comparisons will be included. We anticipate that in most cases usual care within hospital and/or the community will be compared to the intervention.

\section{Outcomes}

Outcomes include those associated with evaluation of multi-component frailty care implementation, including process measures (e.g., measures of fidelity; acceptability; feasibility) targeting any person living with frailty, health service utilization (i.e., readmission, contact with services), health outcomes (e.g., adverse events, morbidity, mortality, institutionalization), economic outcomes (e.g., cost, cost-effectiveness), and patient-oriented measures (e.g., quality of life, well-being, satisfaction with care, caregiver burden).

\section{Study designs}

We will consider all randomized trials (e.g., patient level or cluster), non-randomized controlled trials (e.g., before/after and time-series), observational studies, and cross-sectional studies. Publications will be excluded if a single intervention or no intervention was applied, no evaluation was conducted, if they contain no valid 
Table 3 Valid frailty measures

\begin{tabular}{|c|c|c|}
\hline Measure & Frailty model & Scoring method \\
\hline 11 item Frailty Index [26] & Multidimensional & Predefined fields \\
\hline 5 item Frailty Index (mFl) [27] & Multidimensional & Predefined fields \\
\hline Balance and Muscle Strength [28] & Physical frailty & Functional performance and self-report \\
\hline Beaver Dam Eye Study Measure [29] & Physical frailty & Performance \\
\hline Brief Clinical instrument to Classify Frailty [30] & Multidimensional & Clinician report \\
\hline Brief Frailty Index (bFI) [31] & Multidimensional & Self-report and performance \\
\hline Brief Risk Identification of Geriatric Health Tool (BRIGHT) [32] & Multidimensional & Self-report \\
\hline British Frailty Index [33] & Cumulative deficit & Predefined fields \\
\hline Care Partner derived Frailty Index based on CGA (CP-FI-CGA) [34, 35] & Cumulative deficit & Care partners using predefined fields \\
\hline Chair stands [36] & Physical frailty & Performance \\
\hline $\begin{array}{l}\text { Chinese Canadian Study of Health and Aging Clinical Frailty Scale Telephone } \\
\text { Version [37] }\end{array}$ & Multidimensional & Judgment-based \\
\hline Clinical Frailty Scale (CFS) [5] & Multidimensional & Judgment-based \\
\hline Clinical global impression of change in physical frailty (CGIC-PF) & Cumulative deficit & Predefined fields \\
\hline Comprehensive Assessment of frailty [38] & Physical frailty & Performance, self- and clinician report \\
\hline Comprehensive frailty assessment instrument (CFAl) [39] & Multidimensional & Self-report \\
\hline Continuous Composite Measure of Frailty [40] & Physical frailty & Performance, self-report \\
\hline Continuous frailty scale [41] & Physical frailty & Self-report and Performance \\
\hline EASYcare - short version [42] & Multidimensional & Clinician report \\
\hline EASY-Care Two-step Older persons Screening_Easy-Care TOS [43] & $\begin{array}{l}\text { Multidimensional, } \\
\text { CGA }\end{array}$ & Clinician report \\
\hline Edmonton Frail Scale (EFS) [44] & $\begin{array}{l}\text { Multidimensional, } \\
\text { CGA }\end{array}$ & $\begin{array}{l}\text { Functional performance, self-report, and } \\
\text { clinician report }\end{array}$ \\
\hline Electronic Frailty Index (eFI) [45] & Cumulative deficit & Predefined fields \\
\hline Emergency General Surgeries Frailty Index-EGS-FI [46] & Multidimensional & Clinician report \\
\hline Evaluative Frailty Index for Physical Activity (EFIP) [47] & Cumulative deficit & Clinician report \\
\hline Fatigue, Resistance, Ambulation, Illness, Loss of Weight (FRAIL) [48] & Physical frailty & Self-report \\
\hline Forced Expiratory Volume (FEV1) [49] & Physical frailty & Performance \\
\hline Frail Non Disabled (FIND) [50] & Physical frailty & Self-report \\
\hline FRAIL-Frailty and Autonomy Scoring Instrument of Leuven [51] & Multidimensional & Self-report \\
\hline Frailty Assessment for Care Planning Tool (FACT) [52-54] & $\begin{array}{l}\text { Multidimensional, } \\
\text { CGA }\end{array}$ & Clinician report \\
\hline Frailty GIR Evaluation (FRAGIRE) [55] & Multidimensional & Clinician report \\
\hline Frailty Index (FI) $[56,57]$ & Cumulative deficit & Predefined fields \\
\hline Frailty index derived from comprehensive geriatric assessment (FI-CGA) [58] & $\begin{array}{l}\text { Cumulative deficit, } \\
\text { CGA }\end{array}$ & Trained specialists using predefined fields \\
\hline Frailty Index for Elders (FIFE) [59] & Multidimensional & Clinician report \\
\hline Frailty Phenotype, CHS index [60] & Physical frailty & Self-report and performance \\
\hline $\begin{array}{l}\text { Frailty predicts death One yeaR after Elective CArdiac Surgery Test (FORECAST) } \\
\text { [61] }\end{array}$ & Physical frailty & Performance, self-, and clinician report \\
\hline Frailty Screening Questionnaire (FSQ) [62] & Physical frailty & Self-report \\
\hline Frailty Screening Tool [63] & $\begin{array}{l}\text { Multidimensional, } \\
\text { CGA }\end{array}$ & Self- and clinician report \\
\hline Frailty Trait Scale (FTS) [64] & Physical frailty & Performance \\
\hline Functional Ability Index (FA Index) in the LUCAS Cohort [65] & Physical frailty & Self-report \\
\hline Functional assessment screening package [66] & Multidimensional & Predefined criteria \\
\hline G-8 Geriatric Screening Tool [67] & Multidimensional & Self-report \\
\hline
\end{tabular}


Table 3 Valid frailty measures (Continued)

\begin{tabular}{|c|c|c|}
\hline Measure & Frailty model & Scoring method \\
\hline G8 Questionnaire [68] & $\begin{array}{l}\text { Multidimensional, } \\
\text { CGA }\end{array}$ & Clinician report \\
\hline Gait Speed Test [GST] [69] & Physical frailty & Performance \\
\hline Geriatric Functional Evaluation (GFE) [70] & Multidimensional & Self-report \\
\hline Gérontopôle Frailty Screening Tool (GFST) [71] & Physical frailty & Clinician report \\
\hline Groningen Frailty Indicator (GFI) [72] & Multidimensional & Self-report \\
\hline Guilley Frailty Instrument [73] & Multidimensional & Self-report \\
\hline Hand grip strength [74] & Physical frailty & Performance \\
\hline Health Status Form- HSF [75] & Multidimensional & Self-report \\
\hline Identification of Seniors at Risk (ISAR) [76] & Multidimensional & Self-report \\
\hline Inactivity and Weight Loss [77] & Physical frailty & Clinician report \\
\hline Índice de Vulnerabilidade Clínico-Funcional IVCF-20 [78] & $\begin{array}{l}\text { Multidimensional, } \\
\text { CGA }\end{array}$ & Self-report \\
\hline $\begin{array}{l}\text { Instrumento Multidimensional de rastreio da Sindrome da Fragilidade (IMSIFI) } \\
\text { [79] }\end{array}$ & $\begin{array}{l}\text { Multidimensional, } \\
\text { CGA }\end{array}$ & Clinician report \\
\hline INTER-FRAIL Study Questionnaire [80] & $\begin{array}{l}\text { Multildimensional, } \\
\text { CGA }\end{array}$ & Self-report \\
\hline Kaigo-Yobo CheckList [81] & $\begin{array}{l}\text { Multidimensional, } \\
\text { CGA }\end{array}$ & Self-report \\
\hline Kihon Check-list (KCL) [82] & $\begin{array}{l}\text { Multidimensional, } \\
\text { CGA }\end{array}$ & Self-report \\
\hline KLoSHA Frailty Index [83] & $\begin{array}{l}\text { Multidimensional, } \\
\text { CGA }\end{array}$ & Clinician report \\
\hline Korean Frailty Index [84] & $\begin{array}{l}\text { Multidimensional, } \\
\text { CGA }\end{array}$ & Clinician report \\
\hline Margliano-Cacciafesta polypathological scale (MCPS) [85] & Multidimensional & Clinician report \\
\hline Modelo Fried adaptado [86] & Physical frailty & Self-report \\
\hline Modified Frailty Score [87] & Multidimensional & Performance \\
\hline Modified Physical Performance Test (mPPT) [88] & Physical frailty & Performance \\
\hline Multidimensional Prognostic Index (MPI) [89] & $\begin{array}{l}\text { Multidimensional, } \\
\text { CGA }\end{array}$ & Clinician-report \\
\hline Opasich Frailty Measure [90] & Physical frailty & Performance \\
\hline Physical frailty score [91] & Physical frailty & Performance \\
\hline Predictive Physical Frailty Score [92] & Physical frailty & Self- and clinician report, performance \\
\hline PRISMA-7 [93] & Multidimensional & Self-report \\
\hline Prognostic Frailty Risk Score [94] & $\begin{array}{l}\text { Multidimensional, } \\
\text { CGA }\end{array}$ & Clinician report \\
\hline Prognostic Frailty Score [95] & $\begin{array}{l}\text { Multidimensional, } \\
\text { CGA }\end{array}$ & Self-report and performance \\
\hline Puts Frailty Criteria [96] & Multidimensional & Self-report and performance \\
\hline Rapid Geriatric Assessment (RGA) [97] & Physical frailty & Self-report \\
\hline Reported Edmonton Frail Scale (REFS) [98] & $\begin{array}{l}\text { Multidimensional, } \\
\text { CGA }\end{array}$ & Clinician and self-report \\
\hline Resident Assessment Instrument, Minimum Data Set (RAI-MDS) [99] & $\begin{array}{l}\text { Multidimensional, } \\
\text { CGA }\end{array}$ & Clinician report and performance \\
\hline Rothman Frailty Criteria [100] & Multidimensional & Self-report and performance \\
\hline Schoevaerdts Index [101] & $\begin{array}{l}\text { Multidimensional, } \\
\text { CGA }\end{array}$ & Clinician report \\
\hline SEGAm-Modified Short Emergency Geriatric Assessment [102] & Multidimensional, & Clinician report \\
\hline
\end{tabular}


Table 3 Valid frailty measures (Continued)

\begin{tabular}{|c|c|c|}
\hline Measure & Frailty model & Scoring method \\
\hline & CGA & \\
\hline Self-report Screening Tool for Frailty [103] & Physical frailty & Self-report \\
\hline Self-rated Health Deficits Index (HDI) [104] & Multidimensional & Self-report \\
\hline SHARE Frailty Instrument [105] & Physical frailty & Self-report, calculator \\
\hline SHARE Frailty Instrument 75+ [106] & Physical frailty & Self-report, calculator \\
\hline Sherbrooke Postal Questionnaire (SPQ) [107] & $\begin{array}{l}\text { Multidimensional, } \\
\text { CGA }\end{array}$ & Self-report \\
\hline Short physical performance battery (SPPB) [108] & Physical frailty & Performance \\
\hline Strawbridge questionnaire [109] & Multidimensional & Self-report \\
\hline Study of Osteoporotic Fractures (SOF) Index [110] & Physical frailty & Self-report and performance \\
\hline Subset of Functional Status Questionnaire [111] & Multidimensional & Self-report \\
\hline Three-City Study Frailty Criteria [112] & Multidimensional & Performance \\
\hline Tilburg Frailty Indicator (TFI) [113] & $\begin{array}{l}\text { Multidimensional, } \\
\text { CGA }\end{array}$ & Self-report and performance \\
\hline Timed Up and Go (TUG) [114] & Physical frailty & Performance \\
\hline Trauma-Specific Frailty Index (TSFI) [115] & Cumulative deficit & Predefined fields \\
\hline Triage Risk Screening Tool [116] & $\begin{array}{l}\text { Multidimensional, } \\
\text { CGA }\end{array}$ & Clinician report \\
\hline Upper Extremity Function (UEF) Frailty [117] & Physical frailty & Performance \\
\hline Vulnerable Elders Survey (VES-13) [118] & Multidimensional & Clinician report \\
\hline Winograd Screening Instrument [119] & Physical frailty & Clinician report \\
\hline $\begin{array}{l}\text { Women's Health Initiative Observational Study (WHI-OS) Multicomponent } \\
\text { Measure [120] }\end{array}$ & Physical frailty & Self-report and performance \\
\hline
\end{tabular}

measure of frailty or are limited to a study protocol or review of previous studies.

\section{Quality appraisal}

Studies selected for inclusion will be assessed for risk of bias by two independent reviewers using the Effective Public Healthcare Practice Project instrument to assess the quality of quantitative studies [121]. This instrument has been considered suitable for assessment of risk of bias in systematic reviews where randomized and nonrandomized study designs were included [122, 123]. Disagreements will be resolved by consensus or adjudication of a third party. Summary scores from the instrument will inform synthesis of information and exploration of heterogeneity in study results $[121,124,125]$.

\section{Data extraction}

A data extraction form will be developed and piloted on a sample of included records in Microsoft Office Excel (v. 2016, Microsoft Corporation, Redmond, WA) to ensure adequate capture of characteristics and findings of included studies. One reviewer will extract the data from each primary study independently, then another will verify the accuracy of the extracted data. Disagreements will be settled through discussion with a third author.
The following information will be extracted from each included study:

\section{Study characteristics}

Author, year, publication type, trial registration number, funding source, setting (country, system of health care, acute/community/primary care), theoretical framing, research question(s), aims of study, design, population, sample, recruitment procedure, outcome measures, test statistics, key findings, limitations as noted by authors and reviewers, conclusions as noted by authors, reviewer notes.

\section{Population}

Sample size, inclusion/exclusion, number of enrolled and analyzed, description of cases/controls, reasons for withdrawal, missing data, age, proportion female, ethnicity, reason for admission, frailty definition, measure/instrument to identify of frailty, training for frailty instrument application, co-morbidities (dementia, mildcognitive impairment, known risk for/occurrence of post-treatment delirium, history of falls, occurrence/history of urinary infections/bedsores, other physical health diagnoses, malnutrition), subgroups analyzed in the study. 


\section{Intervention/strategy}

Intervention/strategy name, aim of intervention, intervention description, who delivered the intervention, professionals/others involved, intervention setting, intervention recipient, use of manual/guidelines for intervention, frequency of each intervention component, duration of each intervention component, assessment of fidelity, method of data collection, timing of data collection in relation to intervention, cost of intervention.

\section{Data analysis}

We anticipate a variety of study designs and methods of assessing complex interventions will pose challenges in conducting a meta-analysis. If a meta-analysis is not possible we will pool what data we can, reporting the limitations of our findings. In this case, we will describe findings in a narrative synthesis. To ensure a systematic approach to the narrative synthesis, the guidelines proposed by Cochrane will be adhered to [126]. The narrative will be structured according to study design, type and delivery of interventions, setting, and population. Similarities and differences between findings observed across studies and patterns in data will be outlined. Any data available will be transformed in attempts to find common descriptive and statistical formats for analysis. Within and between study differences will be explored for explanations of direction and size of effects of interventions. Effects of heterogeneity among studies will be discussed, particularly with respect to theoretical framing that may provide explanations for heterogeneity. Finally, the overall strength of the synthesis will be assessed by evaluating the risk of bias results, quality of the evidence, and an overall critical reflection on the synthesis methods [126].

If there are a sufficient number of similar interventions, effects will be pooled using random effects metaanalysis in RevMan (RevMan 5.3 Cochrane). Heterogeneity will be assessed both qualitatively to assess if metaanalysis should be used and measured formally using the I-squared statistic if possible with publication bias assessed using funnel plots. If meta-analysis is used, the following subgroup analyses will be considered: age, setting (e.g., community-based care vs. acute care, teaching vs. community hospitals), and acute ward types (e.g., ICU, medicine, surgical, specialist geriatric units, outpatient, emergency department).

\section{Discussion}

Frailty is a relatively new term, and describes both the state of exaggerated vulnerability associated with agerelated deficit accumulation, and the associated multidimensional syndrome. To be acceptable to clinicians and the patients they serve, frailty must meaningfully inform decisions about care. As the population ages, health care systems face growing numbers of patients with frailty who may derive less benefit or even more harm from aggressive interventions and invasive procedures while adding cost across the system [127, 128]. In present circumstances, where specialist geriatrician resources are limited, the entire health care workforce needs to be empowered with valid methods of screening for frailty and delivering bespoke models of care [129]. Frailty inclusive care pathways may provide useful guidance in the care of older patients living with frailty in hospital, intermediate and community settings, where clinicians may benefit from presentation of precise considerations in specific patient populations (e.g., primary care, emergency department, surgery) who transition between care settings. Consistent frailty screening and application of frailty-inclusive interventions through existing care pathways and routine care may provide meaningful context to all associated decisions and care provided for this vulnerable population.

\section{Limitations}

Despite our aging population and expected increased incidence of frailty across the care continuum, we expect that there will be limited evidence of evaluation of multi-component interventions aimed to improve care and outcomes for people living with frailty. We expanded the search strategy to maximize findings, although results may demonstrate heterogeneous study designs and frailty assessment methods, limiting our ability to pool data and make inferences for practice. Moreover, we did not include patient or public input in our protocol development and may have focused on a limited perspective of frailty inclusive care. Regardless of the potential limitations we are committed to finding evidence of frailty pathways with rigorous evaluation to inform future practice where possible.

\section{Conclusions}

Frailty-inclusive care interventions that can be incorporated into existing pathways for any disease or clinical setting are an essential part of care continuity for people living with frailty. This review will inform future work to develop and implement pathways aiming to improve the care received by this vulnerable population.

\footnotetext{
Abbreviations

CDSR: Cochrane Database of Systematic Reviews; CFS: Clinical Frailty Scale; CGA: Comprehensive Geriatric Assessment; CINAHL: Cumulative Index to Nursing and Allied Health Literature; EMBASE: Excerpta Medica Database; ICTRP: International Clinical Trials Registry Platform; ICU: Intensive care unit; MEDLINE: Medical Literature Analysis and Retrieval System Online; MeSH: Medical Subject Headings; PRISMA-P: Preferred Reporting Items for Systematic Reviews and Meta-Analyses Protocols; PROSPERO: International Prospective Register of Systematic Reviews; SCN: Strategic Clinical Network; WHO: World Health Organization
} 


\section{Supplementary Information}

The online version contains supplementary material available at https://doi. org/10.1186/s13643-021-01638-0.

Additional file 1: Additional Table 1. PRISMA-P (Preferred Reporting Items for Systematic review and Meta-Analysis Protocols) 2015 checklist

\section{Acknowledgements}

The authors acknowledge the following individuals whose input was essential to the completion of this protocol in support of the grant proposal: Marjan Abbasi, Liza Bialy, Diana Keto-Lambert, Rachel Khadaroo, Tara Landry, Sheny Khera, Jasneet Parmar.

\section{Authors' contributions}

$\mathrm{CLM}$ and $\mathrm{GH}$ contributed to writing the draft manuscript. All authors contributed to protocol development. All authors read and approved the final manuscript. All authors confirm their responsibility for its present form. CLM is guarantor of the review.

\section{Funding}

Funding to support this review was provided by a grant from the Alberta Health Services Critical Care Strategic Clinical Network (SCN) 2019 Systematic Review competition. The Government of Alberta provided partial support for involvement by Dr. Montgomery and Dr. Hopkin in the study through a grant to the Network of Alberta Health Economists. The terms of the grants mean they are unrestricted and there was no oversight from the Government of Alberta or Critical Care SCN on the topic, methods, results, or interpretation of the study. There was no involvement of funding organizations in the decision to publish.

\section{Availability of data and materials}

Not applicable.

\section{Declarations}

\section{Ethics approval and consent to participate}

Ethics review is not required by the University of Alberta. The review targets previously published articles. No personally identifiable information will be obtained.

\section{Consent for publication}

Not applicable.

\section{Competing interests}

All authors report no financial relationships with any organizations that might have an interest in the submitted work in the previous 3 years; no other relationships or activities that could appear to have influenced the submitted work.

Carmel Montgomery is supported by a Network of Alberta Health Economists fellowship award and was a 2017 Canadian Frailty Network Interdisciplinary Fellow. Dr. Bagshaw holds a Canada Research Chair in Critical Care Nephrology and is a scientific director for the Alberta Health Services Critical Care Strategic Clinical Network. Dr. Rolfson was a key member of the research group that developed and validated the Edmonton Frail Scale.

\section{Author details}

'Institute of Health Economics, 120010405 Jasper Avenue, Edmonton, Alberta T5J 3N4, Canada. ${ }^{2}$ Department of Critical Care Medicine, Faculty of Medicine and Dentistry, University of Alberta, 2-124 Clinical Sciences Building, 1135083 Ave, Edmonton, Alberta T6G 2G3, Canada. ${ }^{3}$ Critical Care Strategic Clinical Network, Alberta Health Services, Edmonton, Alberta, Canada. ${ }^{4}$ Division of Geriatric Medicine, Department of Medicine, Faculty of Medicine and Dentistry, University of Alberta, 1-198 Clinical Sciences Building, 1135083 Ave, Edmonton, Alberta T6G 2G3, Canada.
Received: 29 July 2020 Accepted: 12 March 2021

Published online: 26 March 2021

\section{References}

1. Romero-Ortuno R, Wallis S, Biram R, Keevil V. Clinical frailty adds to acute illness severity in predicting mortality in hospitalized older adults: an observational study. Eur J Intern Med. 2016;35:24-34. https://doi.org/10.101 6/j.ejim.2016.08.033.

2. Kahlon S, Pederson J, Majumdar SR, Belga S, Lau D, Fradette M, Boyko D, Bakal JA, Johnston C, Padwal RS, McAlister FA. Association between frailty and 30-day outcomes after discharge from hospital. Can Med Assoc J. 2015; 187(11):799-804. https://doi.org/10.1503/cmaj.150100.

3. Clegg A, Young J, lliffe S, Rikkert MO, Rockwood K. Frailty in elderly people. Lancet. 2013;381 (9868):752-62. https://doi.org/10.1016/S0140-6736(12)621 67-9.

4. Kehler DS, Ferguson T, Stammers AN, Bohm C, Arora RC, Duhamel TA, et al. Prevalence of frailty in Canadians 18-79 years old in the Canadian Health Measures Survey. BMC Geriatr. 2017;17(28). https://doi.org/10.1186/s12877017-0423-6.

5. Rockwood K, Song X, Macknight C, Bergman H, Hogan DB, McDowell I, Mitnitski A. A global clinical measure of fitness and frailty in elderly people. CMAJ. 2005;173(5):489-95. https://doi.org/10.1503/cmaj.050051.

6. Hoover M, Rotermann M, Sanmartin C, Bernier J. Validation of an index to estimate the prevalence of frailty among community-dwelling seniors. Health Rep. 2013;24(9):10-7.

7. Hogan DB, Freiheit EA, Strain LA, Patten SB, Schmaltz HN, Rolfson D, Maxwell CJ. Comparing frailty measures in their ability to predict adverse outcome among older residents of assisted living. BMC Geriatr. 2012;12(1): 56. https://doi.org/10.1186/1471-2318-12-56.

8. Bagshaw S, Stelfox H, McDermid R, Rolfson D, Tsuyuki R, Baig N, et al. Association between frailty and short- and long-term outcomes among critically ill patients: a multicentre prospective cohort study. CMAJ. 2014; 186(2):E95-E102. https://doi.org/10.1503/cmaj.130639.

9. Montgomery CL, Zuege DJ, Rolfson DB, Opgenorth D, Hudson D, Stelfox HT, Bagshaw SM. Implementation of population-level screening for frailty among patients admitted to adult intensive care in Alberta, Canada. Can $J$ Anaesth. 2019:66(11):1310-9. https://doi.org/10.1007/s12630-019-01414-8.

10. Montgomery CL, Rolfson DB, Bagshaw SM. Frailty and the association between long-term recovery after intensive care unit admission. Crit Care Clin. 2018;34(4):527-47. https://doi.org/10.1016/j.ccc.2018.06.007.

11. Shamseer L, Moher D, Clarke M, Ghersi D, Liberati A, Petticrew M, et al. Preferred reporting items for systematic review and meta-analysis protocols (PRISMA-P) 2015: Elaboration and explanation. BMJ. 2015;350:g7647.

12. Jackson JL, Kuriyama A, Anton A, Choi A, Fournier JP, Geier AK, Jacquerioz F, Kogan D, Scholcoff C, Sun R. The accuracy of Google Translate for abstracting data from non-English-language trials for systematic reviews. Ann Intern Med. 2019;171(9):677-9. https://doi.org/10.7326/M19-0891.

13. Carpenter CR, Shelton E, Fowler S, Suffoletto B, Platts-Mills TF, Rothman RE, Hogan TM. Risk factors and screening instruments to predict adverse outcomes for undifferentiated older emergency department patients: a systematic review and meta-analysis. Acad Emerg Med. 2015;22(1):1-21. https://doi.org/10.1111/acem.12569.

14. Pialoux T, Goyard J, Lesourd B. Screening tools for frailty in primary health care: a systematic review. Geriatr Gerontol Int. 2012;12(2):189-97. https://doi. org/10.1111/j.1447-0594.2011.00797.x.

15. Clegg A, Rogers $L$, Young J. Diagnostic test accuracy of simple instruments for identifying frailty in community-dwelling older people: a systematic review. Age Ageing. 2015;44(1):148-52. https://doi.org/10.1093/ageing/afu1 57.

16. Aguayo GA, Donneau AF, Vaillant MT, Schritz A, Franco OH, Stranges S, Malisoux L, Guillaume M, Witte DR. Agreement between 35 published frailty scores in the general population. Am J Epidemiol. 2017;186(4):420-34. https://doi.org/10.1093/aje/kwx061.

17. Ambagtsheer RC, Visvanathan R, Dent E, Yu S, Schultz TJ, Beilby J. Commonly used screening instruments to identify frailty among community-dwelling older people in a general practice (primary care) setting: a study of diagnostic test accuracy. J Gerontol A Biol Sci Med Sci. 2020;75(6):1134-42. https://doi.org/10.1093/gerona/glz260.

18. Apostolo J, Cooke R, Bobrowicz-Campos E, Santana S, Marcucci M, Cano A, et al. Predicting risk and outcomes for frail older adults: an umbrella review 
of frailty screening tools. JBI Database System Rev Implement Rep. 2017 15(4):1154-208. https://doi.org/10.11124/JBISRIR-2016-003018.

19. Bouillon K, Kivimaki M, Hamer M, Sabia S, Fransson El, Singh-Manoux A, Gale CR, Batty GD. Measures of frailty in population-based studies: an overview. BMC Geriatr. 2013;13(1):64. https://doi.org/10.1186/1471-2318-13-64.

20. de Vries NM, Staal JB, van Ravensberg CD, Hobbelen JS, Olde Rikkert MG. Nijhuis-van der Sanden MW. Outcome instruments to measure frailty: a systematic review. Ageing Res Rev. 2011;10(1):104-14. https://doi.org/10.101 6/j.arr.2010.09.001

21. Faller JW, Pereira DDN, de Souza S, Nampo FK, Orlandi FS, Matumoto S. Instruments for the detection of frailty syndrome in older adults: a systematic review. PLoS One. 2019;14(4):e0216166. https://doi.org/10.1371/ journal.pone.0216166.

22. Sutton JL, Gould RL, Daley S, Coulson MC, Ward EV, Butler AM, Nunn SP, Howard RJ. Psychometric properties of multicomponent tools designed to assess frailty in older adults: a systematic review. BMC Geriatr. 2016;16(1):55. https://doi.org/10.1186/s12877-016-0225-2.

23. Buta BJ, Walston JD, Godino JG, Park M, Kalyani RR, Xue QL, Bandeen-Roche K, Varadhan R. Frailty assessment instruments: systematic characterization of the uses and contexts of highly-cited instruments. Ageing Res Rev. 2016;26: 53-61. https://doi.org/10.1016/j.arr.2015.12.003.

24. Dent E, Kowal P, Hoogendijk EO. Frailty measurement in research and clinical practice: a review. Eur J Intern Med. 2016;31:3-10. https://doi.org/1 0.1016/j.ejim.2016.03.007.

25. Sternberg SA, Wershof Schwartz A, Karunananthan S, Bergman H, Mark CA The identification of frailty: a systematic literature review. J Am Geriatr Soc. 2011;59(11):2129-38. https://doi.org/10.1111/j.1532-5415.2011.03597.x.

26. Velanovich V, Antoine H, Swartz A, Peters D, Rubinfeld I. Accumulating deficits model of frailty and postoperative mortality and morbidity: its application to a national database. J Surg Res. 2013;183(1):104-10. https:// doi.org/10.1016/j.jss.2013.01.021

27. Chimukangara M, Helm MC, Frelich MJ, Bosler ME, Rein LE, Szabo A, Gould JC. A 5-item frailty index based on NSQIP data correlates with outcomes following paraesophageal hernia repair. Surg Endosc. 2017;31(6):2509-19. https://doi.org/10.1007/s00464-016-5253-7.

28. Dayhoff NE, Suhrheinrich J, Wigglesworth J, Topp R, Moore S. Balance and muscle strength as predictors of frailty among older adults. J Gerontol Nurs. 1998;24(7):18-27; quiz 54-5. https://doi.org/10.3928/0098-9134-19980701-06.

29. Klein BE, Klein R, Knudtson MD, Lee KE. Relationship of measures of frailty to visual function: the Beaver Dam Eye Study. Trans Am Ophthalmol Soc. 2003; 101:191-6 discussion 6-9.

30. Rockwood K, Stadnyk K, MacKnight C, McDowell I, Hebert R, Hogan DB. A brief clinical instrument to classify frailty in elderly people. Lancet. 1999; 353(9148):205-6. https://doi.org/10.1016/S0140-6736(98)04402-X.

31. Freiheit EA, Hogan DB, Eliasziw M, Meekes MF, Ghali WA, Partlo LA, Maxwell CJ. Development of a frailty index for patients with coronary artery disease. J Am Geriatr Soc. 2010;58(8):1526-31. https://doi.org/10.1111/j.1532-5415.2 010.02961.x.

32. Kerse N, Boyd M, McLean C, Koziol-McLain J, Robb G. The BRIGHT tool. Age Ageing. 2008;37(5):553-88. https://doi.org/10.1093/ageing/afn145.

33. Kamaruzzaman S, Ploubidis GB, Fletcher A, Ebrahim S. A reliable measure of frailty for a community dwelling older population. Health Qual Life Outcomes. 2010;8(1):123. https://doi.org/10.1186/1477-7525-8-123.

34. Goldstein J, Hubbard RE, Moorhouse P, Andrew MK. Feasibility of using information derived from a care partner to develop a frailty index based on comprehensive geriatric assessment. J Frailty Aging. 2013;2(1):15-21. https:// doi.org/10.14283/jfa.2013.3.

35. Goldstein J, Hubbard RE, Moorhouse P, Andrew MK, Mitnitski A, Rockwood $K$. The validation of a care partner-derived frailty index based upon comprehensive geriatric assessment (CP-FI-CGA) in emergency medical services and geriatric ambulatory care. Age Ageing. 2015;44(2):327-30. https://doi.org/10.1093/ageing/afu161.

36. Lord SR, Murray SM, Chapman K, Munro B, Tiedemann A. Sit-to-stand performance depends on sensation, speed, balance, and psychological status in addition to strength in older people. J Gerontol A Biol Sci Med Sci. 2002;57(8):M539-43. https://doi.org/10.1093/gerona/57.8.M539.

37. Chan DC, Tsou HH, Chen CY, Chen CY. Validation of the Chinese-Canadian study of health and aging clinical frailty scale (CSHA-CFS) telephone version. Arch Gerontol Geriatr. 2010;50(3):e74-80. https://doi.org/10.1016/j.archger.2009.06.004.

38. Sundermann S, Dademasch A, Praetorius J, Kempfert J, Dewey T, Falk V, et al. Comprehensive assessment of frailty for elderly high-risk patients undergoing cardiac surgery. Eur J Cardiothorac Surg. 2011;39(1):33-7. https://doi.org/10.1016/j.ejcts.2010.04.013.

39. De Witte N, Gobbens R, De Donder L, Dury S, Buffel T, Schols J, et al. The comprehensive frailty assessment instrument: development, validity and reliability. Geriatr Nurs. 2013;34(4):274-81. https://doi.org/10.1016/j. gerinurse.2013.03.002

40. Buchman AS, Wilson RS, Bienias $J$, Bennett DA. Change in frailty and risk of death in older persons. Exp Aging Res. 2009;35(1):61-82. https://doi.org/10.1 080/03610730802545051.

41. Wu C, Geldhof GJ, Xue QL, Kim DH, Newman AB, Odden MC. Development, construct validity, and predictive validity of a continuous frailty scale: results from 2 large US cohorts. Am J Epidemiol. 2018;187(8):1752-62. https://doi. org/10.1093/aje/kwy041.

42. Melis RJ, van Eijken MI, Borm GF, Wensing M, Adang E, van de Lisdonk EH, et al. The design of the Dutch EASYcare study: a randomised controlled trial on the effectiveness of a problem-based community intervention model for frail elderly people [NCT00105378]. BMC Health Serv Res. 2005;5(1):65. https://doi.org/10.1186/1472-6963-5-65.

43. van Kempen JA, Schers HJ, Jacobs A, Zuidema SU, Ruikes F, Robben SH, et al. Development of an instrument for the identification of frail older people as a target population for integrated care. Br J Gen Pract. 2013; 63(608):e225-31. https://doi.org/10.3399/bjgp13X664289.

44. Rolfson DB, Majumdar SR, Tsuyuki RT, Tahir A, Rockwood K. Validity and reliability of the Edmonton Frail Scale. Age Ageing. 2006;35(5):526-9. https://doi.org/10.1093/ageing/afl041.

45. Clegg A, Bates C, Young J, Ryan R, Nichols L, Ann Teale E, Mohammed MA, Parry J, Marshall T. Development and validation of an electronic frailty index using routine primary care electronic health record data. Age Ageing. 2016; 45(3):353-60. https://doi.org/10.1093/ageing/afw039.

46. Joseph B, Zangbar B, Pandit V, Fain M, Mohler MJ, Kulvatunyou N, Jokar TO, O'Keeffe T, Friese RS, Rhee P. Emergency general surgery in the elderly: too old or too frail? J Am Coll Surg. 2016;222(5):805-13. https://doi.org/10.1016/ j.jamcollsurg.2016.01.063

47. de Vries NM, Staal JB, Olde Rikkert MG. Nijhuis-van der Sanden MW. Evaluative frailty index for physical activity (EFIP): a reliable and valid instrument to measure changes in level of frailty. Phys Ther. 2013:93(4):55161. https://doi.org/10.2522/ptj.20120127.

48. Gardiner PA, Mishra GD, Dobson AJ. Validity and responsiveness of the FRAI L scale in a longitudinal cohort study of older Australian women. J Am Med Dir Assoc. 2015;16(9):781-3. https://doi.org/10.1016/j.jamda.2015.05.005.

49. Bortz WM 2nd. A conceptual framework of frailty: a review. J Gerontol A Biol Sci Med Sci. 2002;57(5):M283-8. https://doi.org/10.1093/gerona/57.5.M283.

50. Cesari M, Demougeot L, Boccalon H, Guyonnet S, Abellan Van Kan G, Vellas $B$, et al. A self-reported screening tool for detecting community-dwelling older persons with frailty syndrome in the absence of mobility disability: the FiND questionnaire. PLoS One. 2014;9(7):e101745.

51. De Lepeleire J, Ylieff M, Stessens J, Buntinx F, Paquay L. The validity of the frail instrument in general practice. Arch Public Health. 2004;62(3-4):185-96.

52. Moorhouse P, Mallery LH. Palliative and therapeutic harmonization: a model for appropriate decision-making in frail older adults. J Am Geriatr Soc. 2012; 60(12):2326-32. https://doi.org/10.1111/j.1532-5415.2012.04210.x.

53. Mallery LH, Allen M, Fleming I, Kelly K, Bowles S, Duncan J, Moorhouse P. Promoting higher blood pressure targets for frail older adults: a consensus guideline from Canada. Cleve Clin J Med. 2014;81(7):427-37. https://doi. org/10.3949/ccjm.81a.13110.

54. Moffatt H, Moorhouse P, Mallery L, Landry D, Tennankore K. Using the Frailty Assessment for Care Planning Tool (FACT) to screen elderly chronic kidney disease patients for frailty: the nurse experience. Clin Interv Aging. 2018;13:843-52. https://doi.org/10.2147/CIA.S150673.

55. Vernerey D, Anota A, Vandel P, Paget-Bailly S, Dion M, Bailly V, Bonin M, Pozet A, Foubert A, Benetkiewicz M, Manckoundia P, Bonnetain F. Development and validation of the FRAGIRE tool for assessment an older person's risk for frailty. BMC Geriatr. 2016;16(1):187. https://doi.org/10.1186/ s12877-016-0360-9.

56. Mitnitski AB, Mogilner AJ, Rockwood K. Accumulation of deficits as a proxy measure of aging. Sci World J. 2001;1:323-36. https://doi.org/10.1100/tsw.2 001.58.

57. Searle SD, Mitnitski A, Gahbauer EA, Gill TM, Rockwood K. A standard procedure for creating a frailty index. BMC Geriatr. 2008;8(1):24. https://doi. org/10.1186/1471-2318-8-24. 
58. Jones DM, Song X, Rockwood K. Operationalizing a frailty index from a standardized comprehensive geriatric assessment. J Am Geriatr Soc. 2004; 52(11):1929-33. https://doi.org/10.1111/j.1532-5415.2004.52521.x.

59. Tocchi C, Dixon J, Naylor M, Jeon S, McCorkle R. Development of a frailty measure for older adults: the frailty index for elders. J Nurs Meas. 2014;22(2): 223-40. https://doi.org/10.1891/1061-3749.22.2.223.

60. Fried LP, Tangen CM, Walston J, Newman AB, Hirsch C, Gottdiener J, Seeman T, Tracy R, Kop WJ, Burke G, McBurnie MA. Frailty in older adults: evidence for a phenotype. J Gerontol A Biol Sci Med Sci. 2001;56(3):M14656. https://doi.org/10.1093/gerona/56.3.M146.

61. Sundermann S, Dademasch A, Rastan A, Praetorius J, Rodriguez H, Walther T, Mohr FW, Falk V. One-year follow-up of patients undergoing elective cardiac surgery assessed with the Comprehensive Assessment of Frailty test and its simplified form. Interact Cardiovasc Thorac Surg. 2011;13(2):119-23; discussion 23. https://doi.org/10.1510/icvts.2010.251884

62. Ma L, Tang Z, Chan P, Walston JD. Novel Frailty Screening Questionnaire (FSQ) predicts 8-year mortality in older adults in China. J Frailty Aging. 2019; 8(1):33-8. https://doi.org/10.14283/jfa.2018.38.

63. Doba N, Tokuda Y, Goldstein NE, Kushiro T, Hinohara S. A pilot trial to predict frailty syndrome: the Japanese Health Research Volunteer Study. Exp Gerontol. 2012;47(8):638-43. https://doi.org/10.1016/j.exger.2012.05.016.

64. Garcia-Garcia FJ, Carcaillon L, Fernandez-Tresguerres J, Alfaro A, Larrion JL, Castillo C, et al. A new operational definition of frailty: the Frailty Trait Scale. J Am Med Dir Assoc. 2014;15(5):371 e7-e13.

65. Dapp U, Minder CE, Anders J, Golgert S, von Renteln-Kruse W. Long-term prediction of changes in health status, frailty, nursing care and mortality in community-dwelling senior citizens-results from the Longitudinal Urban Cohort Ageing Study (LUCAS). BMC Geriatr. 2014;14(1):141. https://doi.org/1 0.1186/1471-2318-14-141.

66. Moore AA, Siu AL. Screening for common problems in ambulatory elderly: clinical confirmation of a screening instrument. Am J Med. 1996;100(4):43843. https://doi.org/10.1016/S0002-9343(97)89520-4

67. Bellera CA, Rainfray M, Mathoulin-Pelissier S, Mertens C, Delva F, Fonck M, et al. Screening older cancer patients: first evaluation of the G-8 geriatric screening tool. Ann Oncol. 2012;23(8):2166-72. https://doi.org/10.1093/annonc/mdr587.

68. Baitar A, Van Fraeyenhove F, Vandebroek A, De Droogh E, Galdermans D, Mebis J. Evaluation of the Groningen frailty indicator and the G8 questionnaire as screening tools for frailty in older patients with cancer. J Geriatr Oncol. 2013;4(1):32-8. https://doi.org/10.1016/j.jgo.2012.08.001.

69. Stanaway FF, Gnjidic D, Blyth FM, Le Couteur DG, Naganathan V, Waite L, et al. How fast does the Grim Reaper walk? Receiver operating characteristics curve analysis in healthy men aged 70 and over. BMJ. 2011; 343(dec15 1):d7679. https://doi.org/10.1136/bmj.d7679.

70. Scarcella P, Liotta G, Marazzi MC, Carbini R, Palombi L. Analysis of survival in a sample of elderly patients from Ragusa, Italy on the basis of a primary care level multidimensional evaluation. Arch Gerontol Geriatr. 2005;40(2): 147-56. https://doi.org/10.1016/j.archger.2004.07.004.

71. Vellas B, Balardy L, Gillette-Guyonnet S. Abellan Van Kan G, Ghisolfi-Marque A, Subra J, et al. Looking for frailty in community-dwelling older persons: the Gerontopole Frailty Screening Tool (GFST). J Nutr Health Aging. 2013; 17(7):629-31. https://doi.org/10.1007/s12603-013-0363-6.

72. Metzelthin SF, Daniels R, van Rossum E, de Witte L, van den Heuvel WJ, Kempen $\mathrm{Gl}$. The psychometric properties of three self-report screening instruments for identifying frail older people in the community. BMC Public Health. 2010;10(1):176. https://doi.org/10.1186/1471-2458-10-176.

73. Guilley E, Ghisletta P, Armi F, Berchtold A, d'Epinay CL, Michel J-P, et al. Dynamics of frailty and $\mathrm{ADL}$ dependence in a five-year longitudinal study of octogenarians. Res Aging. 2008;30(3):299-317. https://doi.org/10.1177/0164027507312115.

74. Wu IC, Shiesh SC, Kuo PH, Lin XZ. High oxidative stress is correlated with frailty in elderly chinese. J Am Geriatr Soc. 2009;57(9):1666-71. https://doi. org/10.1111/j.1532-5415.2009.02392.x.

75. Brody KK, Johnson RE, Douglas RL. Evaluation of a self-report screening instrument to predict frailty outcomes in aging populations. Gerontologist. 1997;37(2):182-91. https://doi.org/10.1093/geront/37.2.182.

76. McCusker J, Bellavance F, Cardin S, Trepanier S, Verdon J, Ardman O. Detection of older people at increased risk of adverse health outcomes after an emergency visit: the ISAR screening tool. J Am Geriatr Soc. 1999; 47(10):1229-37. https://doi.org/10.1111/j.1532-5415.1999.tb05204.x.

77. Chin A, Paw MJ, de Groot LC, van Gend SV, Schoterman MH, Schouten EG, et al. Inactivity and weight loss: effective criteria to identify frailty. J Nutr Health Aging. 2003;7(1):55-60.
78. Moraes EN, Carmo JA, Moraes FL, Azevedo RS, Machado CJ, Montilla DE. Clinical-Functional Vulnerability Index-20 (IVCF-20): rapid recognition of frail older adults. Rev Saude Publica. 2016;50:81.

79. Lindôso ZCL. Elaboração de um instrumento multidimensional para o rastreio de síndrome da fragilidade em idosos atendidos na atenção primaria. Brasil: Pontifícia Universidade Católica do Rio Grande do Sul; 2010.

80. Di Bari M, Profili F, Bandinelli S, Salvioni A, Mossello E, Corridori C, et al. Screening for frailty in older adults using a postal questionnaire: rationale, methods, and instruments validation of the INTER-FRAIL study. J Am Geriatr Soc. 2014;62(10):1933-7. https://doi.org/10.1111/jgs.13029.

81. Shinkai S, Watanabe N, Yoshida H, Fujiwara Y, Amano H, Lee S, Nishi M, Tsuchiya Y. Research on screening for frailty: development of "the KaigoYobo Checklist". Nihon Koshu Eisei Zasshi. 2010;57(5):345-54.

82. Ogawa K, Fujiwara Y, Yoshida H, Nishi M, Fukaya T, Kim M, Amano H, Lee S, Watanabe N, Shinkai S. The validity of the "Kihon Check-list" as an index of frailty and its biomarkers and inflammatory markers in elderly people. Nihon Ronen Igakkai Zasshi. 2011;48(5):545-52. https://doi.org/10.3143/geriatrics.48. 545.

83. Jung HW, Kim SW, Ahn S, Lim JY, Han JW, Kim TH, Kim KW, Kim Kl, Kim CH. Prevalence and outcomes of frailty in Korean elderly population: comparisons of a multidimensional frailty index with two phenotype models. PLoS One. 2014;9(2):e87958. https://doi.org/10.1371/journal.pone. 0087958.

84. Hwang HS, Kwon IS, Park BJ, Cho B, Yoon JL, Won CW. The validity and reliability of Korean Frailty Index. J Korean Geriatri Soc. 2010;14(4):191-202. https://doi.org/10.4235/jkgs.2010.14.4.191.

85. Amici A, Baratta A, Linguanti A, Giudice G, Servello A, Scalise C, Tafaro L, Cicconetti P, Marigliano V, Cacciafesta M. The Marigliano-Cacciafesta polypathological scale: a tool for assessing fragility. Arch Gerontol Geriatr. 2008;46(3):327-34. https://doi.org/10.1016/j.archger.2007.05.007.

86. Nunes DP, Duarte YA, Santos JL, Lebrao ML. Screening for frailty in older adults using a self-reported instrument. Rev Saude Publica. 2015:49:2.

87. Hubbard RE, O'Mahony MS, Woodhouse KW. Characterising frailty in the clinical setting--a comparison of different approaches. Age Ageing. 2009; 38(1):115-9. https://doi.org/10.1093/ageing/afn252.

88. Brown $M$, Sinacore DR, Binder EF, Kohrt WM. Physical and performance measures for the identification of mild to moderate frailty. J Gerontol A Biol Sci Med Sci. 2000;55(6):M350-5. https://doi.org/10.1093/gerona/55.6.M350.

89. Pilotto A, Rengo F, Marchionni N, Sancarlo D, Fontana A, Panza F, Ferrucci L, on behalf of the FIRI-SIGG Study Group. Comparing the prognostic accuracy for all-cause mortality of frailty instruments: a multicentre 1-year follow-up in hospitalized older patients. PLoS One. 2012;7(1):e29090. https://doi.org/1 0.1371/journal.pone.0029090.

90. Opasich C, Patrignani A, Mazza A, Gualco A, Cobelli F, Pinna GD. An elderlycentered, personalized, physiotherapy program early after cardiac surgery. Eur J Cardiovasc Prev Rehabil. 2010;17(5):582-7. https://doi.org/10.1097/HJR. 0b013e3283394977.

91. Gill TM, Baker DI, Gottschalk M, Peduzzi PN, Allore H, Byers A. A program to prevent functional decline in physically frail, elderly persons who live at home. N Engl J Med. 2002;347(14):1068-74. https://doi.org/10.1056/NEJMoa020423.

92. Carriere I, Colvez A, Favier F, Jeandel C, Blain H. group Es. Hierarchical components of physical frailty predicted incidence of dependency in a cohort of elderly women. J Clin Epidemiol. 2005;58(11):1180-7. https://doi. org/10.1016/j.jclinepi.2005.02.018.

93. Raiche M, Hebert R, Dubois MF. PRISMA-7: a case-finding tool to identify older adults with moderate to severe disabilities. Arch Gerontol Geriatr. 2008;47(1):9-18. https://doi.org/10.1016/j.archger.2007.06.004.

94. Pijpers E, Ferreira I, van de Laar RJ, Stehouwer CD, Nieuwenhuijzen Kruseman AC. Predicting mortality of psychogeriatric patients: a simple prognostic frailty risk score. Postgrad Med J. 2009;85(1007):464-9. https:// doi.org/10.1136/pgmj.2008.073353.

95. Ravaglia G, Forti P, Lucicesare A, Pisacane N, Rietti E, Patterson C. Development of an easy prognostic score for frailty outcomes in the aged. Age Ageing. 2008;37(2):161-6. https://doi.org/10.1093/ageing/afm195.

96. Puts MT, Monette J, Girre V, Wolfson C, Monette M, Batist G, et al. Does frailty predict hospitalization, emergency department visits, and visits to the general practitioner in older newly-diagnosed cancer patients? Results of a prospective pilot study. Crit Rev Oncol Hematol. 2010;76(2):142-51. https:// doi.org/10.1016/j.critrevonc.2009.10.006.

97. Morley JE, Adams EV. Rapid geriatric assessment. J Am Med Dir Assoc. 2015; 16(10):808-12. https://doi.org/10.1016/j.jamda.2015.08.004. 
98. Hilmer SN, Perera V, Mitchell S, Murnion BP, Dent J, Bajorek B, Matthews S, Rolfson DB. The assessment of frailty in older people in acute care. Australas J Ageing. 2009;28(4):182-8. https://doi.org/10.1111/j.1741-6612.2009.00367.x.

99. Hirdes JP, Fries BE, Morris JN, Steel K, Mor V, Frijters D, LaBine S, Schalm C, Stones MJ, Teare G, Smith T, Marhaba M, Pérez E, Jónsson P. Integrated health information systems based on the RAI/MDS series of instruments. Healthc Manage Forum. 1999;12(4):30-40. https://doi.org/10.1016/S0840-4 704(10)60164-0

100. Rothman MD, Leo-Summers L, Gill TM. Prognostic significance of potential frailty criteria. J Am Geriatr Soc. 2008;56(12):2211-6. https://doi.org/10.1111/ j.1532-5415.2008.02008.x.

101. Schoevaerdts D, Biettlot S, Malhomme B, Rezette C, Gillet JB, Vanpee D, et al. Early identification of the geriatric profile in the emergency department: presentation of the Short Emergency Geriatric Assessment (SEGA). Rev Gériatrie. 2004;29:169-76.

102. Oubaya N, Mahmoudi R, Jolly D, Zulfiqar AA, Quignard E, Cunin C, et al. Screening for frailty in elderly subjects living at home: validation of the Modified Short Emergency Geriatric Assessment (SEGAm) instrument. J Nutr Health Aging. 2014;18(8):757-64. https://doi.org/10.1007/s12603-014-0541-1.

103. Barreto PS, Greig C, Ferrandez A. Detecting and categorizing frailty status in older adults using a self-report screening instrument. Arch Gerontol Geriatr. 2012;53(3):e249-e54

104. Lucicesare A, Hubbard RE, Fallah N, Forti P, Searle SD, Mitnitski A, Ravaglia G, Rockwood K. Comparison of two frailty measures in the Conselice Study of Brain Ageing. J Nutr Health Aging. 2010;14(4):278-81. https://doi.org/10.1 007/s12603-010-0061-6.

105. Romero-Ortuno R, Walsh CD, Lawlor BA, Kenny RA. A frailty instrument for primary care: findings from the Survey of Health, Ageing and Retirement in Europe (SHARE). BMC Geriatr. 2010;10(1):57. https://doi.org/10.1186/1471-231 8-10-57.

106. Romero-Ortuno R, Soraghan C. A Frailty Instrument for primary care for those aged 75 years or more: findings from the Survey of Health, Ageing and Retirement in Europe, a longitudinal population-based cohort study (SHARE-FI75+). BMJ Open. 2014;4(12):e006645. https://doi.org/10.1136/ bmjopen-2014-006645.

107. Hebert R, Bravo G, Korner-Bitensky N, Voyer L. Predictive validity of a posta questionnaire for screening community-dwelling elderly individuals at risk of functional decline. Age Ageing. 1996;25(2):159-67. https://doi.org/10.1 093/ageing/25.2.159

108. Guralnik JM, Simonsick EM, Ferrucci L, Glynn RJ, Berkman LF, Blazer DG, Scherr PA, Wallace RB. A short physical performance battery assessing lower extremity function: association with self-reported disability and prediction of mortality and nursing home admission. J Gerontol. 1994;49(2):M85-94. https://doi.org/10.1093/geronj/49.2.M85

109. Matthews M, Lucas A, Boland R, Hirth V, Odenheimer G, Wieland D, Williams $H$, Paul Eleazer $G$. Use of a questionnaire to screen for frailty in the elderly: an exploratory study. Aging Clin Exp Res. 2004;16(1):34-40. https://doi.org/1 $0.1007 / B F 03324529$.

110. Ensrud KE, Ewing SK, Cawthon PM, Fink HA, Taylor BC, Cauley JA, Dam TT, Marshall LM, Orwoll ES, Cummings SR, for the Osteoporotic Fractures in Men Research Group. A comparison of frailty indexes for the prediction of falls, disability, fractures, and mortality in older men. J Am Geriatr Soc. 2009; 57(3):492-8. https://doi.org/10.1111/j.1532-5415.2009.02137.x.

111. Maly RC, Hirsch SH, Reuben DB. The performance of simple instruments in detecting geriatric conditions and selecting community-dwelling older people for geriatric assessment. Age Ageing. 1997;26(3):223-31. https://doi. org/10.1093/ageing/26.3.223

112. Avila-Funes JA, Amieva H, Barberger-Gateau P, Le Goff M, Raoux N, Ritchie K, et al. Cognitive impairment improves the predictive validity of the phenotype of frailty for adverse health outcomes: the three-city study. J Am Geriatr Soc. 2009;57(3):453-61. https://doi.org/10.1111/j.1532-5415.2008.0213 $6 . x$

113. Gobbens RJ, van Assen MA, Luijkx KG, Wijnen-Sponselee MT, Schols JM. The Tilburg Frailty Indicator: psychometric properties. J Am Med Dir Assoc. 2010; 11(5):344-55. https://doi.org/10.1016/j.jamda.2009.11.003.

114. Podsiadlo D, Richardson S. The timed "Up \& Go": a test of basic functional mobility for frail elderly persons. J Am Geriatr Soc. 1991;39(2):142-8. https:// doi.org/10.1111/j.1532-5415.1991.tb01616.x.

115. Joseph B, Pandit V, Zangbar B, Kulvatunyou N, Tang A, O'Keeffe T, et al. Validating trauma-specific frailty index for geriatric trauma patients: a prospective analysis. J Am Coll Surg. 2014;219(1):10-7 e1. https://doi.org/1 0.1016/j.jamcollsurg.2014.03.020.

116. Duc S, Fernandez C, Moheb B, Dang VM, Bloch F, Floccia M, et al. Triage risk screening tool (TRST) in screening elderly patients requiring the intervention of a mobile geriatric team: results of a pilot study. Geriatr Psychol Neuropsychiatr Vieil. 2015;13(1):55-62.

117. Toosizadeh N, Mohler J, Najafi B. Assessing upper extremity motion: an innovative method to identify frailty. J Am Geriatr Soc. 2015;63(6):1181-6. https://doi.org/10.1111/jgs.13451.

118. Saliba D, Elliott M, Rubenstein LZ, Solomon DH, Young RT, Kamberg CJ, Carol Roth RN, MacLean CH, Shekelle PG, Sloss EM, Wenger NS. The vulnerable elders survey: a tool for identifying vulnerable older people in the community. J Am Geriatr Soc. 2001;49(12):1691-9. https://doi.org/10.104 6/j.1532-5415.2001.49281.x

119. Winograd $\mathrm{CH}$, Gerety MB, Chung M, Goldstein MK, Dominguez F Jr, Vallone R. Screening for frailty: criteria and predictors of outcomes. J Am Geriatr Soc 1991;39(8):778-84. https://doi.org/10.1111/j.1532-5415.1991.tb02700.x.

120. Woods NF, LaCroix AZ, Gray SL, Aragaki A, Cochrane BB, Brunner RL, et al. Frailty: emergence and consequences in women aged 65 and older in the Women's Health Initiative Observational Study. J Am Geriatr Soc. 2005;53(8): 1321-30. https://doi.org/10.1111/j.1532-5415.2005.53405.x.

121. Thomas BH, Ciliska D, Dobbins M, Micucci S. A process for systematically reviewing the literature: providing the research evidence for public health nursing interventions. Worldviews Evid-Based Nurs. 2004;1(3):176-84. https:// doi.org/10.1111/j.1524-475X.2004.04006.X.

122. Deeks JJ, Dinnes J, D'Amico R, Sowden AJ, Sakarovitch C, Song F, et al. Evaluating non-randomised intervention studies. Health Technol Assess. 2003;7(27):iii-x 1-173.

123. Jackson N, Waters E. Guidelines for Systematic Reviews in Health P, Public Health T. Criteria for the systematic review of health promotion and public health interventions. Health Promot Int. 2005;20(4):367-74. https://doi.org/1 0.1093/heapro/dai022

124. Thomas B, Ciliska D, Dobbins M, Micucci S. Effective public healthcare Panacea Project Quality Assessment Tool for Quantitative Studies. Available from: https://www.ephpp.ca/quality-assessment-tool-for-quantitativestudies/. Accessed 22 Mar 2021.

125. Armijo-Olivo S, Stiles C, Hagen N, Biondo P, Cummings G. Assessment of study quality for systematic reviews: a comparison of the Cochrane Collaboration Risk of Bias Tool and the Effective Public Health Practice Project Quality Assessment Tool: methodological research. J Eval Clin Pract. 2012;18(1):12-8. https://doi.org/10.1111/j.1365-2753.2010.01516.x.

126. Ryan R. Cochrane Consumers and Communication Review Group: data synthesis and analysis 2013. Available from: http://cccrg.cochrane.org.

127. Deschka H, Schreier R, El-Ayoubi L, Erler S, Muller D, Alken A, et al. Prolonged intensive care treatment of octogenarians after cardiac surgery: a reasonable economic burden? Interact Cardiovasc Thorac Surg. 2013;17(3): 501-6. https://doi.org/10.1093/icvts/ivt229.

128. Wilkes JG, Evans JL, Prato BS, Hess SA, MacGillivray DC, Fitzgerald TL. Frailty cost: economic impact of frailty in the elective surgical patient. J Am Coll Surg. 2019;228(6):861-70. https://doi.org/10.1016/j.jamcollsurg.2019.01.015.

129. Heckman GA, Molnar FJ, Lee L. Geriatric medicine leadership of health care transformation: to be or not to be? Can Geriatr J. 2013;16(4):192-5.

\section{Publisher's Note}

Springer Nature remains neutral with regard to jurisdictional claims in published maps and institutional affiliations.

Ready to submit your research? Choose BMC and benefit from:

- fast, convenient online submission

- thorough peer review by experienced researchers in your field

- rapid publication on acceptance

- support for research data, including large and complex data types

- gold Open Access which fosters wider collaboration and increased citations

- maximum visibility for your research: over $100 \mathrm{M}$ website views per year

At $\mathrm{BMC}$, research is always in progress.

Learn more biomedcentral.com/submissions 